\title{
Copaiba Oil Suppresses Inflammatory Cytokines in Splenocytes of C57Bl/6 Mice Induced with Experimental Autoimmune Encephalomyelitis (EAE)
}

\author{
Débora S. Dias ${ }^{1}$, Lívia B. A. Fontes ${ }^{1,3}$, Antônio E. M. Crotti ${ }^{2}$, Beatriz J. V. Aarestrup ${ }^{3}$, \\ Fernando M. Aarestrup ${ }^{3}$, Ademar A. da Silva Filho ${ }^{1, *}$ and José O. A. Corrêa ${ }^{1, *}$
}

1 Department of Pharmaceutical Sciences, Faculty of Pharmacy, Federal University of Juiz de Fora, Juiz de Fora, R. José Lourenço Kelmer s/n, Campus Universitário, 36036-900 Juiz de Fora, MG, Brazil

2 Departamento de Química, Faculdade de Filosofia, Ciências e Letras de Ribeirão Preto, Universidade de São Paulo, 14040-901 Ribeirão Preto, SP, Brazil

3 Laboratory of Experimental Imunology and Patology, CBR, Federal University of Juiz de Fora, Juiz de Fora, R. José Lourenço Kelmer s/n, Campus Universitário, 36036-900 Juiz de Fora, MG, Brazil

* Authors to whom correspondence should be addressed;

E-Mails: ademar.alves@ufjf.edu.br (A.A.S.F.); joacorrea@gmail.com (J.O.A.C.);

Tel.: +55-32-2102-3893 (A.A.S.F.); Fax: +55-32-2102-3801 (J.O.A.C).

Received: 16 May 2014; in revised form: 8 August 2014 / Accepted: 13 August 2014 /

Published: 21 August 2014

\begin{abstract}
Experimental autoimmune encephalomyelitis (EAE) is a murine autoimmune disease used to study multiple sclerosis. We have investigated the immunomodulatory effects of copaiba oil (100, 50 and $25 \mu \mathrm{g} / \mathrm{mL})$ on NO, $\mathrm{H}_{2} \mathrm{O}_{2}$, TNF- $\alpha$, IFN- $\gamma$ and IL-17 production in cultured cells from EAE-mice. Copaiba oil $(100 \mu \mathrm{g} / \mathrm{mL})$ inhibited $\mathrm{H}_{2} \mathrm{O}_{2}, \mathrm{NO}$, IFN- $\gamma$ TNF- $\alpha$ and IL-17 production spontaneously or after ConA and $\mathrm{MOG}_{35-55}$ stimulation. It is suggested that copaiba oil acts on the mechanism of development of EAE by IFN- $\gamma$, IL-17 and TNF- $\alpha$ inhibition, modulating the immune response on both Th1 and Th17 cells.
\end{abstract}

Keywords: multiple sclerosis; experimental autoimmune encephalomyelitis; natural products; immunomodulatory; copaiba oil 


\section{Introduction}

Multiple sclerosis (MS) is an autoimmune inflammatory and chronic disease of the central nervous system (CNS) characterized by multifocal demyelinating lesions in the white matter, gliosis and subsequent diffuse axonal damage, which results in a progressive neurological function deficit [1]. MS affects more than 2.5 million people worldwide, representing one of the major causes of disability and socio-economic impact, mainly in young women [2]. However, the etiology of MS is not completely understood and its treatment is expensive and possess limited efficacy [3]. Therefore, the development of more effective drugs would be of great clinical benefit in the treatment of MS.

The experimental autoimmune encephalomyelitis (EAE) is an appropriate model for the study of the underlying pathogenesis of MS, since it resembles MS in its clinical, histopathological, and immunological features. It is known that the immunopathogenesis of both EAE and MS is immune-mediated mainly by Th1 and Th17 cells. If Th1 cells are stimulated, some cytokines are produced, such as interferon gamma (INF- $\gamma$ ) and tumor necrosis factor-alpha (TNF- $\alpha$ ). On the other hand, Th17 cells activate mainly the production of IL-17, while both cells (Th1 and Th17) induce the production of oxygen radicals, such as nitric oxide (NO) and hydrogen peroxide $\left(\mathrm{H}_{2} \mathrm{O}_{2}\right)$. As a result, new therapies for the treatment of MS are focused on drugs that are able to modulate the production of inflammatory mediators [4-6].

In this context, natural products have shown an important role in the development of new drugs, mainly immunomodulatory and anti-inflammatory compounds [7,8]. Among natural samples with potential therapeutic applications on MS, is copaiba oil (COP), which is obtained by tapping the trunk of the trees from several species of Copaifera L. (Leguminosae), popularly known as "copaiba" or "pau-de-óleo". Copaiba oil has been used by Indians from the Northern and Northeastern parts of Brazil, especially in Amazonas State, as anti-inflammatory and anti-septic, as well as for healing wounds [4]. Copaiba oil also constitutes one of the most important renewable sources of natural remedy for populations of the Amazon region. Nowadays, copaiba oil can be found in drugstores and markets all over Brazil [9].

Besides its use in traditional medicine, studies have demonstrated that copaiba oil can ameliorate the outcome of some inflammatory-mediated diseases, such as gastrointestinal and pulmonary afflictions [10]. Copaiba oil was also able to inhibit both paw edema induced by carrageenan [11], and NO production induced by lipopolysaccharide (LPS) in macrophages [9]. Moreover, copaiba oil has been reported to reduce neutrophil recruitment and microglia activation, as well as to induce neuroprotection in the CNS by modulating an acute inflammatory response [6]. These findings suggest that copaiba oil may also inhibit inflammatory responses involved in both MS and EAE. However, copaiba oil has never been evaluated in inflammatory mediators involved in EAE and most of studies on copaiba oil are related to its chemical composition, thus the aim of this study was to evaluate the immunomodulatory effects of copaiba oil on $\mathrm{H}_{2} \mathrm{O}_{2}$, NO, IFN- $\gamma$, TNF- $\alpha$ and IL-17 production in culture of splenocytes from $\mathrm{C} 57 \mathrm{Bl} / 6$ mice induced with EAE. 


\section{Results and Discussion}

\subsection{GC-MS Analysis}

The chemical composition of the copaiba oil (COP) as identified by GC-MS is shown in Table 1 . The identification of these compounds was performed by comparison of their mass spectra with those of the Wiley 7 and NIST 08, spectral libraries, as well as by comparison of their retention indexes with those in the literature [12-15]. A total of 25 compounds were identified, namely twenty-three sesquiterpene hydrocarbons and two sesquiterpene alcohols. $\beta$-Caryophyllene $(\mathbf{1}, 24.9 \%)$, $\delta$-cadinene (2, 15.3\%), allo-aromadendrene $(3,7.5 \%), \beta$-bisabolene $(4,6.3 \%)$ and $\alpha$-cadinene $(5,5.6 \%)$ were identified as the major constituents in COP (Figure 1). These sesquiterpenes have also been previously identified in other samples of COP that have also been reported to display anti-inflammatory activity.

Table 1. Chemical composition of the COP identified by GC-MS.

\begin{tabular}{cccccc}
\hline Compound & RT (min) & RI $_{\text {exp }}$ & RI $_{\text {lit }}$ & \% RA & Identification \\
\hline$\delta$-Elemene & 21.18 & 1344 & 1339 & 0.5 & RI, MS \\
$\alpha$-Ylangene & 22.52 & 1379 & 1372 & 0.6 & RI, MS \\
$\delta$-Copaene & 22.69 & 1383 & 1376 & 0.6 & RI, MS \\
$\beta$-Elemene & 23.37 & 1401 & 1393 & 3.2 & RI, MS \\
$\alpha$-Gurjunene & 23.66 & 1408 & 1409 & 3.3 & RI, MS \\
$\beta$-Caryophyllene & 24.44 & 1429 & 1428 & 24.9 & RI, MS \\
trans- $\alpha$-Bergamotene & 24.66 & 1435 & 1436 & 4.9 & RI, MS \\
$\alpha$-Guaiene & 24.96 & 1443 & 1439 & 4.2 & RI, MS \\
$\alpha$-Humulene & 25.34 & 1453 & 1455 & 2.6 & RI, MS \\
allo-Aromadendrene & 25.75 & 1464 & 1461 & 7.5 & RI, MS \\
$\gamma$-Gurjunene & 26.26 & 1478 & 1477 & 0.3 & RI, MS \\
9-epi-Caryophyllene & 26.49 & 1484 & 1478 & 0.8 & RI, MS \\
Germacrene D & 26.56 & 1486 & 1480 & 0.3 & RI, MS \\
$\beta$-Selinene & 26.66 & 1488 & 1485 & 0.9 & RI, MS \\
Germacrene B & 26.99 & 1497 & 1499 & 5.1 & RI, MS \\
$\alpha$-Muurolene & 27.08 & 1500 & 1499 & 2.6 & RI, MS \\
$\beta$-Bisabolene & 27.32 & 1506 & 1509 & 6.3 & RI, MS \\
$\delta$-Amorphene & 27.46 & 1510 & 1512 & 4.8 & RI, MS \\
$\gamma$-Cadinene & 27.68 & 1516 & 1513 & 0.8 & RI, MS \\
$\delta$-Cadinene & 27.91 & 1523 & 1524 & 15.3 & RI, MS \\
$\beta$-Sesquiphellandrene & 28.05 & 1527 & 1524 & 1.1 & RI, MS \\
$\alpha$-Cadinene & 28.32 & 1534 & 1531 & 5.6 & RI, MS \\
Selina-3,7-(11)-diene & 28.78 & 1547 & 1545 & 0.1 & RI, MS \\
Elemol & 28.54 & 1540 & 1547 & 0.5 & RI, MS \\
Caryophyllenyl alcohol & 28.95 & 1552 & 1550 & 4.7 & RI, MS \\
Hydrocarbon sesquiterpenes & & & & 94.8 & \\
Oxygenated sesquiterpenes & & & & 5.2 & \\
\hline & & & & \\
\hline & & & & \\
\hline
\end{tabular}

$\mathbf{R I}_{\text {exp }}$ : Retention index determined relative to $n$-alkanes $\left(\mathrm{C}_{8}-\mathrm{C}_{20}\right)$ on the Rtx-5MS column. $\mathbf{R I}_{\text {lit }}$ : Retention index from the literature. RA: relative area calculated from the peak area relative to the total peak area. Compound identification: RI, comparison of the RI with those of the literature; MS, comparison of the mass spectra with those of the Wiley 7 and NIST 08 spectral libraries, as well as with those of the literature. 
Figure 1. Chemical structures of the major constituents of Copaifera oil (COP) identified by GC-MS.

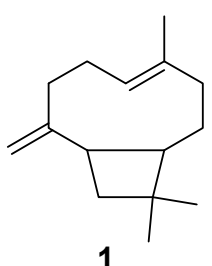

1<smiles>CC1=CC2C(=C(C)CCC2C(C)C)CC1</smiles>

2<smiles></smiles>

3

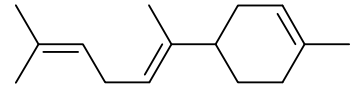

4<smiles>CC1=CC2C(C)=CCC(C(C)C)C2CC1</smiles>

5

\subsection{In Vitro Effect of Copaiba Oil in Splenocyte Culture}

\subsubsection{Levels of Oxygen Radicals ( $\mathrm{NO}$ and $\mathrm{H}_{2} \mathrm{O}_{2}$ )}

Considering the spontaneous production, EAE group (EAEg) produced significant levels of NO and $\mathrm{H}_{2} \mathrm{O}_{2}$ in comparison with basal production of the negative control group (C) (Figure 2a,b). NO production (Figure 2a) was significantly inhibited by the treatment with copaiba oil $(100 \mu \mathrm{g} / \mathrm{mL})$ in comparison with EAE group $(P<0.001)$. Copaiba oil $(100$ and $50 \mu \mathrm{g} / \mathrm{mL})$ also significantly inhibited $\mathrm{H}_{2} \mathrm{O}_{2}$ production (Figure $2 \mathrm{~b}$ ) in comparison with EAE group. Taking into consideration ConA and $\mathrm{MOG}_{35-55}$ stimulus, $\mathrm{NO}$ and $\mathrm{H}_{2} \mathrm{O}_{2}$ production was significantly inhibited by copaiba oil at 50 and $100 \mu \mathrm{g} / \mathrm{mL}$ (Figure 2a,b).

Figure 2. Oxygen radicals production, $\mathrm{NO}$ (a) and $\mathrm{H}_{2} \mathrm{O}_{2}$ (b), by mouse splenocytes incubated with copaiba oil $(100,50$ and $25 \mu \mathrm{g} / \mathrm{mL})$. Mouse splenocytes from non-immunized and untreated mice were used as negative control group (C) and splenocytes from EAE-mice were used as EAE control group (EAEg). Groups presented as $(+)$ were also stimulated with ConA and $\mathrm{MOG}_{35-55}$. After incubation, supernatants were collected and $\mathrm{H}_{2} \mathrm{O}_{2}$ and $\mathrm{NO}$ were measured. Data are presented as mean $\pm \mathrm{SD}$. $* P<0.05 ; * * P<0.01$, $* * * P<0.001$.

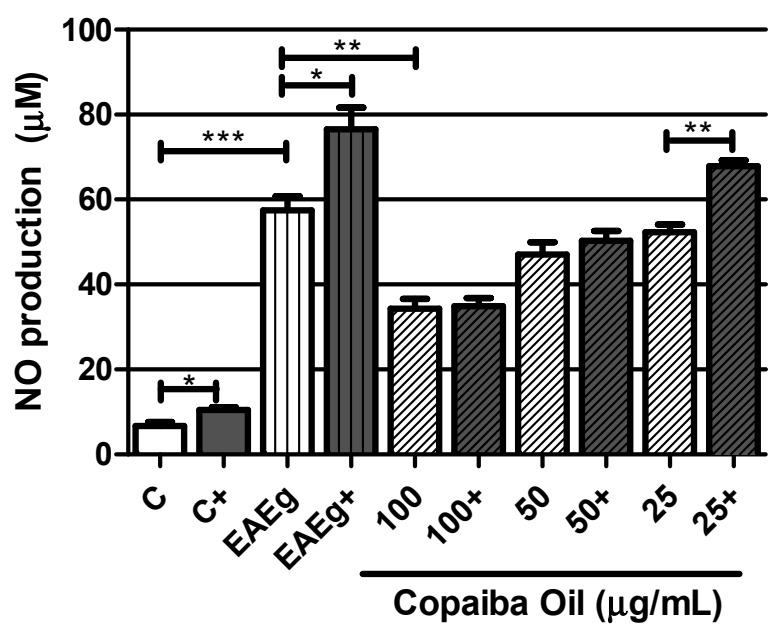

(a)

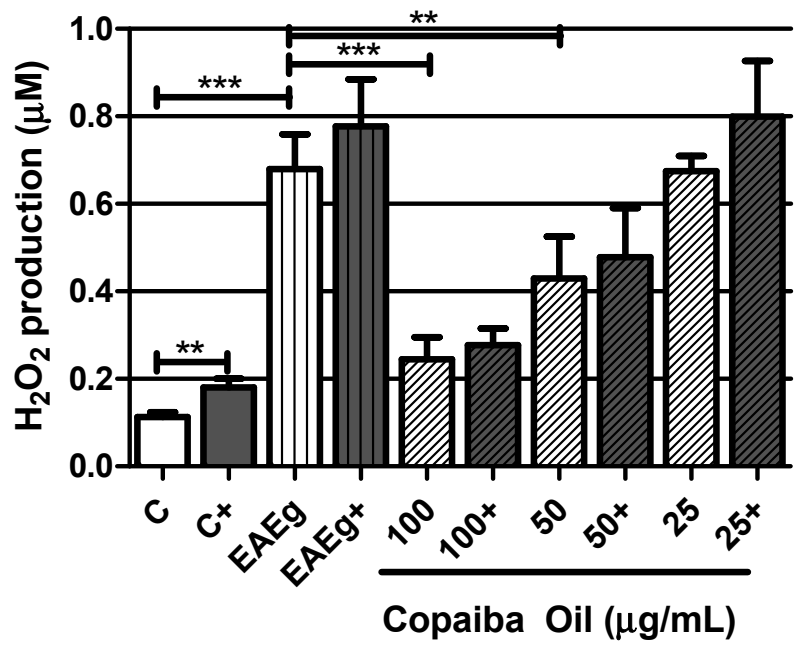

(b) 


\subsubsection{Cytokine Production}

Higher levels of TNF- $\alpha$, IFN- $\gamma$ and IL-17 were observed in the EAE group (EAEg) when compared with the negative control group (C) (Figure 3a-c). Also, levels of TNF- $\alpha$, IFN- $\gamma$ and IL-17 (Figure 3a-c) in spontaneous groups were significantly reduced after treatment with copaiba oil $(100$ and $50 \mu \mathrm{g} / \mathrm{mL})$ in comparison with the EAE group (EAEg). Regarding to ConA and $\mathrm{MOG}_{35-55}$ stimulation, copaiba oil, at $100 \mu \mathrm{g} / \mathrm{mL}$, was able to inhibit TNF- $\alpha$, IFN- $\gamma$ and IL-17 production (Figure 3a,b).

Figure 3. Production of TNF- $\alpha$ (a), INF- $\gamma$ (b) and IL-17 (c) by mouse splenocytes incubated with copaiba oil (100, 50 and $25 \mu \mathrm{g} / \mathrm{mL})$. Mouse splenocytes from non-immunized and untreated mice were used as negative control group (C) and splenocytes from EAE-mice were used as EAE control group (EAEg). Groups presented as $(+)$ were also stimulated with ConA and $\mathrm{MOG}_{35-55}$. After $24 \mathrm{~h}$ of incubation, supernatants were collected and cytokine production was measured with a $440 \mathrm{~nm}$ filter using ELISA method. Data are presented as mean $\pm \mathrm{SD}$. * $P<0.05 ; * * P<0.01, * * * P<0.001$.

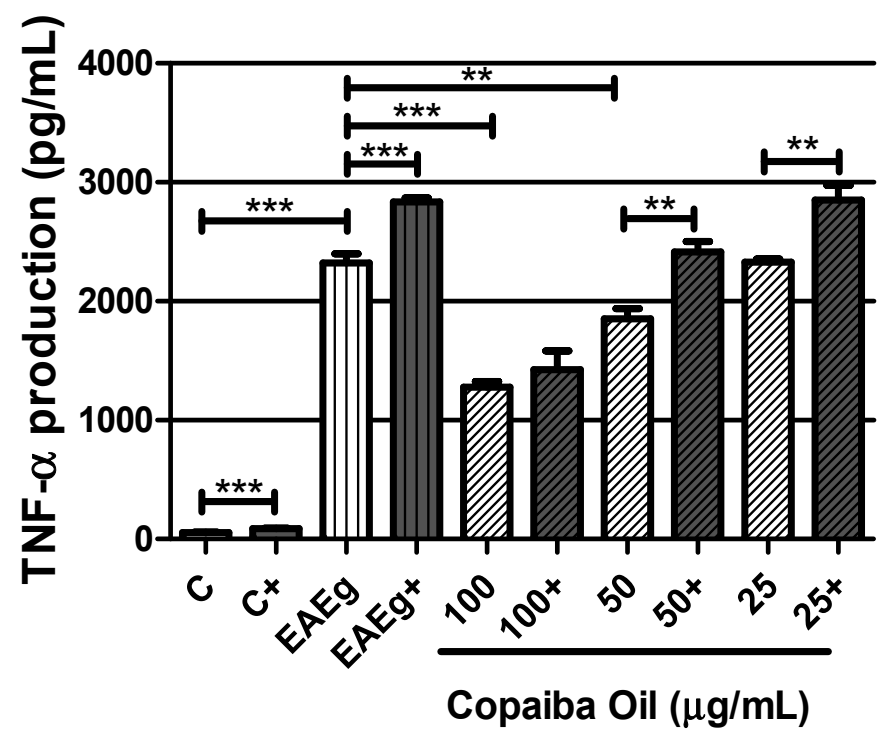

(a)

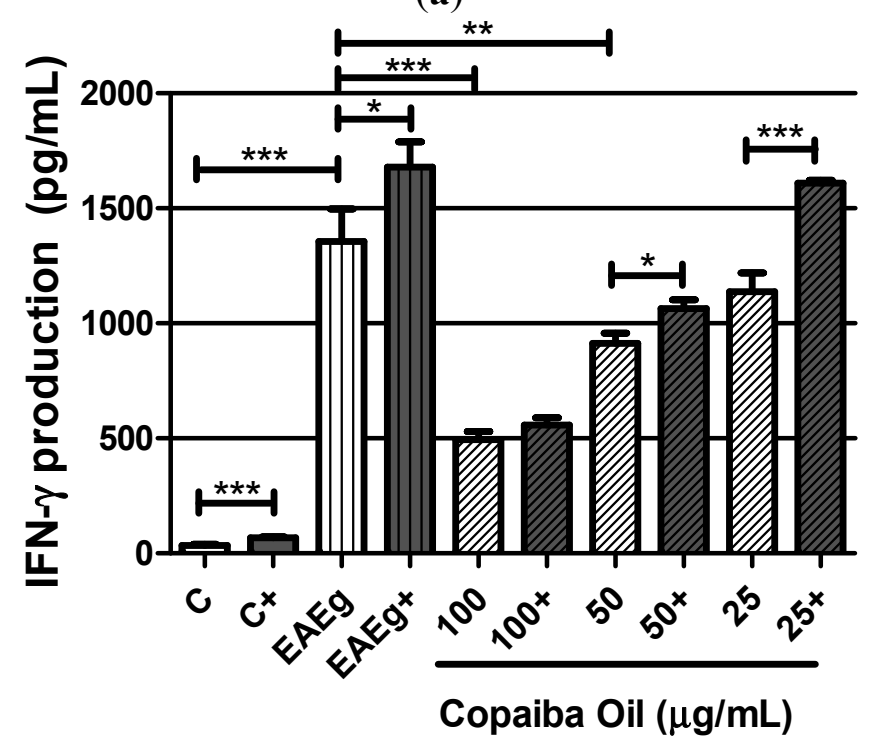

(b) 
Figure 3. Cont.

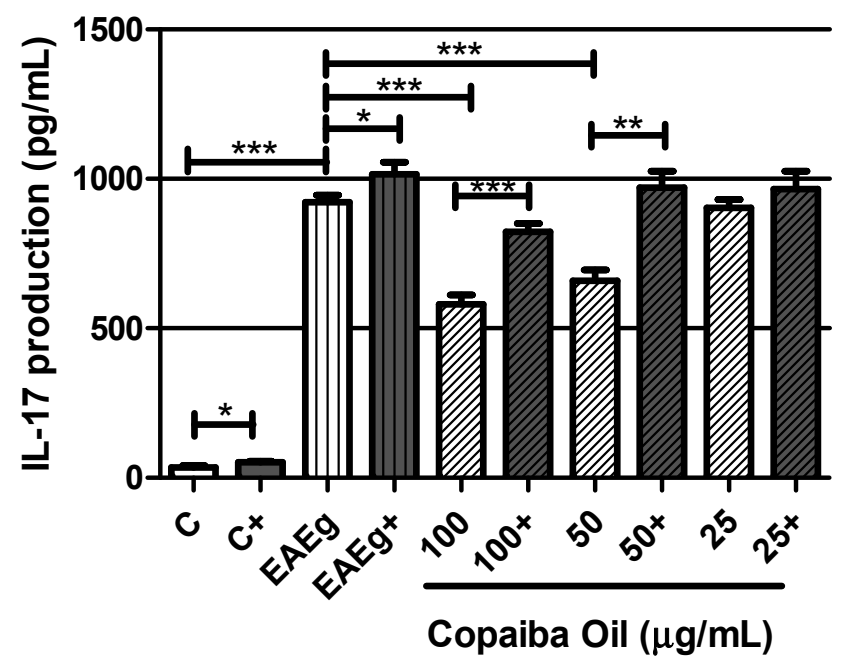

(c)

\subsubsection{Discussion}

Previous studies have shown that copaiba oil ameliorates the outcome of several inflammatory-mediated diseases, such as in the CNS. In addition, copaiba oil is able to inhibit NF- $\mathrm{B}$ translocation, and consequently the secretion of some cytokines, such as IL-6 and TNF- $\alpha$ [8,16-18], which are important inflammatory markers present in the immunopathogenesis of MS [19-21]. Recently, it was reported that copaiba oil is capable to induce neuroprotection in the CNS by modulating the acute inflammatory response, reducing neutrophil recruitment and microglia activation [6]. Those data encouraged us to investigate the immunomodulatory effects of copaiba oil on EAE.

First, EAE was induced in C57B1/6 mice and splenocytes were obtained after 20 days of $\mathrm{MOG}_{35-55}$ immunization, because, in this model, the maximum immune response occurs around day 17 th until 20th after induction of EAE [4,22]. Then, the spontaneous or stimulated (ConA and $\mathrm{MOG}_{35-55}$ ) production of oxygen radicals $\left(\mathrm{H}_{2} \mathrm{O}_{2}\right.$ and NO) and cytokines (TNF- $\alpha$, IFN- $\gamma$ and IL-17) were analyzed after in vitro incubation with non cytotoxic concentrations of copaiba oil [9]. Our results showed that splenocytes, from EAE groups, displayed high levels of oxygen radicals and cytokines in comparison with the negative control group. These findings are in accordance with previous studies [4,17], in which TNF- $\alpha$, INF- $\gamma$ and IL-17 production was increased in cultured splenocytes obtained from non-treated EAE mice.

In addition, our results showed that both $\mathrm{H}_{2} \mathrm{O}_{2}$ and $\mathrm{NO}$ production were significantly reduced after in vitro treatment with copaiba oil (mainly at $100 \mu \mathrm{g} / \mathrm{mL}$ ). It is known that $\mathrm{H}_{2} \mathrm{O}_{2}$, under physiological conditions, is generated in small quantities and rapidly degraded. However, long exposures and high concentrations of this mediator can destroy biological structures and lead to irreversible cell damage, as observed in MS and EAE [23]. Similarly to $\mathrm{H}_{2} \mathrm{O}_{2}$, NO is also responsible for injury to myelin sheath in both MS and EAE [24]. Besides, NO has cytotoxic and cytostatic properties and it is produced in large amounts by macrophages and other immune cells [24]. Regarding this, previous studies showed that copaiba oil reduces the in vitro NO production by peritoneal mouse macrophages stimulated with LPS [9]. 
Moreover, we observed that, mainly at the two highest tested concentrations, copaiba oil was also able to reduce IFN- $\gamma$, TNF- $\alpha$ and IL-17 production by splenocytes.

Cytokines play an essential role in the establishment and maintenance of autoimmune disorders, such as in MS and EAE [3]. T lymphocytes are characterized by IFN- $\gamma$ production, which is the cytokine involved in both macrophage activation and $\mathrm{T}$ cell differentiation in naïve $\mathrm{CD} 4^{+} \mathrm{Th} 1$ cells [25]. Furthermore, IFN- $\gamma$ is related to the severity of the EAE protocol, as well as it regulates the functions of $\mathrm{T}$ lymphocytes, playing an important role in autoimmune diseases, such as MS [22,26]. Similarly, TNF- $\alpha$ is a cytokine present in Th1 and Th17 cells that plays a central role in both EAE and MS [16,26,27].

It has been reported that copaiba oil was able to inhibit both the NF-kB nuclear translocation and the release of pro-inflammatory cytokines (IL-1 $\beta$, IL-6, TNF- $\alpha$ ), in a dose-dependent manner, by LPS-stimulated human THP-1 monocytes, which is in accordance with our findings for TNF- $\alpha$ [18]. However, this is the first report showing that copaiba oil is able to decrease IFN- $\gamma$ and IL-17 generations.

Also, it is important to point out that copaiba oil was able to inhibit $\mathrm{H}_{2} \mathrm{O}_{2}$, NO, TNF- $\alpha$ and IFN- $\gamma$ production after stimulation with ConA and $\mathrm{MOG}_{35-55}$, demonstrating that, even after cellular stimuli, copaiba oil exerted strong suppressive activities in these oxygen radicals and cytokines.

Regarding its chemical composition, all identified compounds by GC-MS in copaiba oil were known from other copaiba oil samples and match those already reported on literature $[9,18]$. $\beta$-Caryophyllene was the main detected compound, which is in agreement with previous chromatographic studies that have shown $\beta$-caryophyllene as the major compound found in copaiba oil samples $[10,11]$.

According to the literature, $\beta$-caryophyllene is a putative candidate as the main anti-inflammatory compound in copaiba oil [6]. In the carrageenan-induced paw edema model, $\beta$-caryophyllene diminished the production of prostaglandin $\mathrm{E}_{2}, \mathrm{TNF}-\alpha$ release and the expression of inducible nitric oxide synthase [28]. Recently, it was demonstrated that this compound acts as a potent, selective and non-psychoactive full agonist for the cannabinoid type-2 ( $\mathrm{CB}(2))$ receptor [29]. Also, previous in vitro studies has demonstrated that $\beta$-caryophyllene binds selectively to $\mathrm{CB}_{2}$ receptor, inhibiting pro-inflammatory pathways, including toll-like receptor complex CD14/TLR4/MD2, which usually leads to the expression of IL-1 $\beta$, IL-6, TNF- $\alpha$ [29]. The $\mathrm{CB}_{2}$ receptor is primarily considered to be expressed in immune or various immune-derived cells, such as $\mathrm{T}$ and $\mathrm{B}$ lymphocytes, leukocytes, macrophages and microglia in the brain [30,31]. In these immune cells types, $\mathrm{CB}_{2}$ agonists mediate various immunosuppressive effects, which may limit the inflammatory response, and consequent associated tissue injury in a large number of pathological conditions [30,31]. Considering all this evidence, $\beta$-caryophyllene may be one of the active compounds related to the immunomodulatory activity of copaiba oil. However, taking into account that copaiba oil is a mixture of several compounds, synergistic or additive effects between $\beta$-caryophyllene and other chemical constituents in the copaiba oil might occur, so that the immunomodulatory activity of copaiba oil may be related to the combination of these compounds. Considering the underlying pathogenesis of EAE and MS, copaiba oil is a potential natural product that should be investigated in the in vivo EAE model. 


\section{Experimental}

\subsection{Copaiba Oil}

Copaiba oil (from Copaifera officinalis, Fabaceae-Caesalpinioideae) was purchased from the university pharmacy (ALL 46,999, All Chemistry, São Paulo, Brazil), at Federal University of Juiz de Fora. Copaiba oil was submitted to a chromatographic analysis to define its composition before use in the experiments.

\subsection{CG Analysis}

Copaiba Oil (COP) was analyzed by GC-MS on a Shimadzu QP2010 Plus (Shimadzu Corporation, Kyoto, Japan) system equipped with an AOC-20i autosampler operating in the electron ionization (EI) mode at $70 \mathrm{eV}$ under the following conditions: Restek Rtx-5MS fused silica capillary column (30 $\mathrm{m} \times 0.25 \mathrm{~mm}$ i.d. $\times 0.25 \mu \mathrm{m}$ film thickness) composed of 5\%-phenyl-95\%-methylpolysiloxane; carrier gas helium $(99.999 \%)$ at a constant flow of $1.0 \mathrm{~mL} / \mathrm{min}$; sample injection volume of $0.1 \mu \mathrm{L}$ (split ratio of 1:10); injector temperature $240{ }^{\circ} \mathrm{C}$; ion-source temperature $280{ }^{\circ} \mathrm{C}$. The oven temperature was programmed to increase from 60 to $240{ }^{\circ} \mathrm{C}$ at $3{ }^{\circ} \mathrm{C} / \mathrm{min}$. Mass spectra were recorded with a scan interval of $0.5 \mathrm{~s}$ within the mass range 40-600 Da. Quantification of each constituent was estimated by internal normalization (\%). The identification of the copaiba oil components was based on their retention indices, relative to a homologous series of $n$-alkanes $\left(\mathrm{C}_{8}-\mathrm{C}_{20}\right)$ measured on an Rtx-5MS capillary column under the same operating conditions. Computer matching was accomplished with the aid of the Wiley 7 and NIST 08 spectra libraries [32]. The mass spectra of the constituents were also compared to those reported in the literature [12].

\subsection{Animals}

Female C57B1/6 mice (21-23 g; 8-12 weeks old), were obtained from the animal care facilities at the Federal University of Juiz de Fora (CBR/UFJF) and maintained in microisolator cages. All animal care and experimental protocols were approved by the Ethical Committee for Animal Care of the Federal University of Juiz de Fora (Protocol n . 039/2010).

\subsection{EAE Induction}

Groups of five mice were subcutaneously (s.c.) immunized at the tail base with $100 \mu \mathrm{g}$ of myelin oligodendrocyte glycoprotein peptide (MOG) ${ }_{35-55}$ (Sigma Chemical Co., Saint Louis, MO, USA), emulsified with complete Freund's adjuvant (CFA) (Sigma Chemical Co.) (v/v), and supplemented with $400 \mu \mathrm{g}$ of attenuated Mycobacterium tuberculosis H37RA (Difco, Detroit, MI, USA). Pertussis toxin (Sigma Chemical Co.), $300 \mathrm{ng} / \mathrm{animal}$, was injected intraperitoneally (i.p.) on the day of immunization and $48 \mathrm{~h}$ later [4]. Non-immunized mice were used as control.

\subsection{Obtainment of Splenocytes, Culture and Treatments}

On the day 20 after induction of EAE, mice were euthanized under deepening anesthesia (i.p.), and the spleens were removed. Cells were obtained by maceration of spleens, and were cultured 
$\left(2 \times 10^{6} / \mathrm{mL}\right)$ in RPMI 1640 medium (Sigma Chemical Co.), supplemented with $5 \%$ heat-inactivated fetal bovine serum, $2 \mathrm{mM}$ L-glutamine, $100 \mathrm{U} / \mathrm{mL}$ penicillin, and $100 \mu \mathrm{g} / \mathrm{mL}$ streptomycin, in a humidified incubator, at $37{ }^{\circ} \mathrm{C}$ and $5 \% \mathrm{CO}_{2}$ atmosphere. Splenocytes were incubated in the presence or absence of $\mathrm{MOG}_{35-55}$ peptide $(10 \mu \mathrm{g} / \mathrm{mL})$ and concanavalin A (ConA, $10 \mu \mathrm{g} / \mathrm{mL}$ ) (Sigma Chemical Co.). Simultaneously at $\mathrm{MOG}_{35-55}$ and ConA stimulation, cells were treated with copaiba oil at 100, 50 and $25 \mu \mathrm{g} / \mathrm{mL}$, which are in vitro non-cytotoxic concentrations, as previously reported [9]. EAE groups (immunized cells) were used as positive control, while the negative control group (C), which cells were obtained from non-immunized mice, received a similar volume of vehicle $(5 \%$ tween 80 in saline). After treatments, supernatants were collected, and $\mathrm{NO}, \mathrm{H}_{2} \mathrm{O}_{2}$, IFN- $\gamma$, IL-17 and TNF- $\alpha$ were measured.

\section{6. $\mathrm{H}_{2} \mathrm{O}_{2}$ Measurement}

Hydrogen peroxide $\left(\mathrm{H}_{2} \mathrm{O}_{2}\right)$ production by splenocytes was assessed according to the adapted method of peroxidase-dependent oxidation of phenol red [33]. Briefly, after $2 \mathrm{~h}$ incubation, suspensions of splenocytes were mixed with a solution containing $5.5 \mathrm{mM}$ dextrose, $0.5 \mathrm{mM}$ phenol red, $19 \mathrm{U} / \mathrm{mL}$ horseradish peroxidase type I RZ 1.0 (Sigma Chemical Co. reaction was stopped by adding $10 \mu \mathrm{L}$ of $\mathrm{NaOH}$ solution $(1 \mathrm{~N})$ per well, and the absorbance was measured at $620 \mathrm{~nm}$ with a microplate reader (TP Reader NM, Termoplate, Palm City, FL, USA). Results were expressed as $\mu \mathrm{M}$ of $\mathrm{H}_{2} \mathrm{O}_{2} / 2 \times 10^{6}$ splenocytes.

\subsection{Nitric Oxide (NO) Measurement}

Splenocytes were incubated for $48 \mathrm{~h}$ and supernatants were removed. NO production was measured according to Griess method [34], which assesses accumulation of nitrite. Briefly, supernatants were mixed with an equal volume of Griess reagent, which was prepared by mixing one part of $0.1 \%(\mathrm{w} / \mathrm{v})$ $\mathrm{N}-(1$-naphthyl)ethylenediamine with one part of $1 \%(\mathrm{w} / \mathrm{v})$ sulfanilamide in 5\% phosphoric acid. After $20 \mathrm{~min}$, absorbance was measured at $540 \mathrm{~nm}$ using a microplate reader (TP Reader NM). Nitrite concentration was calculated using sodium nitrite as standard.

\subsection{Determination of Cytokines Production}

Concentrations of TNF- $\alpha$, IL-17, and IFN- $\gamma$ in supernatants of splenocytes were measured by ELISA method after $24 \mathrm{~h}$ of incubation, according to the manufacturer's recommendation (PeProtech Inc., Rocky Hill, NJ, USA). The following solution was applied to visualize binding: $100 \mu \mathrm{L}$ of ABTS (3-ethylbenzthiazoline-6-sulphonate) (Sigma Chemical Co.) dissolved in $0.05 \mathrm{M}$ citrate buffer ( $\mathrm{pH} 4.0$ ) with $0.01 \% \mathrm{H}_{2} \mathrm{O}_{2}$. The optical density was measured at $405 \mathrm{~nm}$ with a microplate reader (TP Reader NM). The levels of sensitivity for TNF- $\alpha$, IL-17, and IFN- $\gamma$ kits were $16 \mathrm{pg} / \mathrm{mL}$ (according to the manufacturer's information). 


\subsection{Statistics Analysis}

Data are expressed as mean \pm S.E.M and represent at least three independent experiments. All data were analyzed by two-way ANOVA (GraphPad InStat 3.10 software), followed by Student's $t$-test, and differences were considered significant at $P<0.05$.

\section{Conclusions}

The present study has demonstrated, for the first time, an in vitro immunomodulatory effect of copaiba oil on the inflammatory mediators $\mathrm{H}_{2} \mathrm{O}_{2}, \mathrm{NO}$, IFN- $\gamma$, TNF- $\alpha$ and IL-17 produced by splenocytes of EAE-mice. Considering that copaiba oil is a promising natural product for the treatment of inflammatory and demyelinating diseases, such as MS, further studies are in progress to disclose its in vivo effects on an EAE model.

\section{Acknowledgments}

This work was supported by grants from the Fundação de Apoio a Pesquisa do Estado de Minas Gerais (FAPEMIG, CBBAPQ 04257/10 and APQ 00171/11), and the Programa de Apoio à Instalação de Doutores-UFJF, Brazil. We are thankful to PIBIC/CNPq/UFJF, CNPQ and CAPES for fellowships and scholarships.

\section{Author Contributions}

The contributions of the respective authors are as follows: D.S. Dias and Lívia B.A. Fontes did the biological assays, interpreted the results and help to prepare the manuscript. A.A. da Silva Filho interpreted the chemical and biological results and prepared the manuscript. A.E.M. Crotti did GC-MS analysis and interpreted the chemical results. B.J.V. Aarestrup and F.M. Aarestrup interpreted the biological results. José O.A. Corrêa did the biological assays and help to prepare the manuscript, hence the corresponding author. All authors read and approved the final manuscript.

\section{Conflicts of Interest}

The authors declare that they have no conflicts of interest.

\section{References}

1. Zorzella-Pezavento, S.F.G.; Chiuso-Minicucci, F.; Ishikawa, L.L.W.; da Rosa, L.C.; Marques, C.; Ikoma, M.R.V.; Sartori, A. Persistent inflammation in the CNS during chronic EAE despite local absence of Il-17 production. Mediat. Inflamm. 2013, 2013, doi:10.1155/2013/519627.

2. Gasperini, C.; Ruggieri, S.; Mancinelli, C.R.; Pozzilli, C. Advances in the treatment of relapsing-remitting multiple sclerosis - Critical appraisal of Fingolimod. Ther. Clin. Risk Manag. 2013, 9, 73-85.

3. Corrêa, J.O.D.A.; Aarestrup, B.J.V.; Aarestrup, F.M. Effect of thalidomide and pentoxifylline on experimental autoimmune encephalomyelitis (EAE). Exp. Neurol. 2010, 226, 15-23. 
4. Alves, C.C.S.; Castro, S.B.R.; Costa, C.F.; Dias, A.T.; Alves, C.J.; Rodrigues, M.F.; Teixeira, H.C.; Almeida, M.V.; Ferreira, A.P. Anthraquinone derivative o,o'-bis-(3'-iodopropyl)1,4-dihidroxyanthraquinone modulates immune response and improves experimental autoimmune encephalomyelitis. Int. Immunopharmacol. 2012, 14, 127-132.

5. Pöllinger, B. IL-17 producing T cells in mouse models of multiple sclerosis and rheumatoid arthritis. J. Mol. Med. 2012, 90, 613-624.

6. Guimarães-Santos, A.; Santos, D.S.; Santos, I.R.; Lima, R.R.; Pereira, A.; de Moura, L.S.; Carvalho, R.N., Jr.; Lameira, O.; Gomes-Leal, W. Copaiba oil-resin treatment is neuroprotective and reduces neutrophil recruitment and microglia activation after motor cortex excitotoxic injury. Evid.-Based Complement. Alternat. Med. 2012, 2012, doi:10.1155/2012/918174.

7. Da Silva Filho, A.A.; Bueno, P.C.P.; Gregório, L.E.; Silva, M.L.A.; Albuquerque, S.; Bastos, J.K. In vitro trypanocidal activity evaluation of crude extract and isolated compounds from Baccharis dracunculifolia D.C. (Asteraceae). J. Pharm. Pharmacol. 2004, 56, 1195-1199.

8. Newman, D.J.; Cragg, G.M. Natural products as sources of new drugs over the 30 years from 1981 to 2010. J. Nat. Prod. 2012, 75, 311-335.

9. Veiga Junior, V.F.; Rosas, E.C.; Carvalho, M.V.; Henriques, M.G.M.O.; Pinto, A.C. Chemical composition and anti-inflammatory activity of copaiba oils from Copaifera cearensis huber ex Ducke, Copaifera reticulata Ducke and Copaifera multijuga Hayne-A comparative study. J. Ethnopharmacol. 2007, 112, 248-254.

10. Leandro, L.M.; Vargas, F.S.; Barbosa, P.C.S.; Neves, J.K.O.; Silva, J.A.; Veiga-Junior, V.F. Chemistry and biological activities of terpenoids from Copaiba (Copaifera spp.) oleoresins. Molecules 2012, 17, 3866-3889.

11. Veiga-Junior, V.F.; Zunino, L.; Calixto, J.B.; Patitucci, M.L.; Pinto, A.C. Phytochemical and antioedematogenic studies of commercial copaiba oils available in Brazil. Phytother. Res. 2001, $15,476-480$.

12. Adams, R.P. Identification of Essential Oils Components by Gas Chromatography/Mass Spectrometry; Allured Publishing Corporation: Carol Stream, IL, USA, 2005; p. 4.

13. Deus, R.J.A.; Carvalho, A.S.C.; Banna, D.A.D.S.; Arruda, M.S.P.; Alves, C.N.; Santos, A.S. In vitro fungitoxic effect of the oil-resin and the essential oil of copaíba (Copaifera multijuga Hayne). Rev. Bras. Plantas Med. 2009, 11, 347-353.

14. Barbosa, P.C.S.; Medeiros, R.S.; Sampaio, P.T.B.; Vieira, G.; Wiedemann, L.S.M.; Veiga-Júnior, V.F. Influence of abiotic factors on the chemical composition of copaíba oil (Copaifera multijuga Hayne): Soil composition, seasonality and diameter at breast height. J. Braz. Chem. Soc. 2012, 23, 1823-1833.

15. Trindade, F.T.T.; Stabeli, R.G.; Pereira, A.A.; Facundo, V.A.; Silva, A.A. Copaifera multijuga ethanolic extracts, oilresin and its derivatives display larvicidal activity against Anopheles darlingi and Aedes aegypti (Diptera: Culicidae). Rev. Bras. Farmacogn. 2013, 23, 464-470.

16. Chen, X.; Pi, R.; Zou, Y.; Liu, M.; Ma, X.; Jiang, Y.; Mao, X.; Hu, X. Attenuation of experimental autoimmune encephalomyelitis in $\mathrm{C} 57 \mathrm{bl} / 6$ mice by osthole, a natural coumarin. Eur. J. Pharmacol. 2010, 629, 40-46. 
17. Dutra, R.C.; de Cezaro de Souza, P.R.; Bento, A.F.; Marcon, R.; Bicca, M.A.; Pianowski, L.F.; Calixto, J.B. Euphol prevents experimental autoimmune encephalomyelitis in mice: Evidence for the underlying mechanisms. Biochem. Pharmacol. 2012, 83, 531-542.

18. Gelmini, F.; Beretta, G.; Anselmi, C.; Centini, M.; Magni, P.; Ruscica, M.; Cavalchini, A.; Maffei Facino, R. GC-MS profiling of the phytochemical constituents of the oleoresin from Copaifera langsdorffii desf. and a preliminary in vivo evaluation of its antipsoriatic effect. Int. J. Pharm. 2013, 440, 170-178.

19. Barfod, L.; Kemp, K.; Hansen, M.; kharazmi, A. Chalcones from Chinese liquorice inhibit proliferation of $\mathrm{T}$ cells and production of cytokines. Int. Immunopharmacol. 2002, 2, 545-555.

20. Furusawa, J.; Funakoshi-Tago, M.; Tago, K.; Mashino, T.; Inoue, H.; Sonoda, Y.; Kasahara, T. Licochalcone A significantly suppresses LPS signaling pathway through the inhibition of NF-kB p65 phosphorylation at serine 276. Cell. Signal. 2009, 21, 778-785.

21. Funakoshi-Tago, M.; Tago, K.; Nishizawa, C.; Takahashi, K.; Mashino, T.; Iwata, S.; Inoue, H.; Sonoda, Y.; Kasahara, T. Licochalcone $\mathrm{A}$ is a potent inhibitor of TEL-Jak2-mediated transformation through the specific inhibition of Stat3 activation. Biochem. Pharmacol. 2008, 76, 1681-1693.

22. Castro, S.B.R.; Junior, C.O.R.; Alves, C.C.S.; Dias, A.T.; Alves, L.L.; Mazzoccoli, L.; Mesquita, F.P.; Figueiredo, N.S.V.; Juliano, M.A.; Castañon, M.C.M.N.; et al. Immunomodulatory effects and improved prognosis of experimental autoimmune encephalomyelitis after O-tetradecanoyl-genistein treatment. Int. Immunopharmacol. 2012, 12, 465-470.

23. Linker, R.A.; Lee, D.H.; Ryan, S.; van Dam, A.M.; Conrad, R.; Bista, P.; Zeng, W.; Hronowsky, X.; Buko, A.; Chollate, S.; et al. Fumaric acid esters exert neuroprotective effects in neuroinflammation via activation of the Nrf2 antioxidant pathway. Brain 2010, 34, 678-692.

24. Leiper J.; Nandi, M. The therapeutic potential of targeting endogenous inhibitors of nitric oxide synthesis. Nat. Rev. Drug Discov. 2011, 10, 277-291.

25. Lee, E.; Chanamara, S.; Pleasure, D.; Soulika, A.M. IFN-gamma signaling in the central nervous system controls the course of experimental autoimmune encephalomyelitis independently of the localization and composition of inflammatory foci. J. Neuroinflamm. 2012, 9, 7. doi:10.1186/1742-2094-9-7.

26. Rodgers J.M.; Miller S.D. Cytokine control of inflammation and repair in the pathology of multiple sclerosis. Yale J. Biol. Med. 2012, 85, 447-468.

27. Wang X.; Ma, C.; Wu, J.; Zhu, J. Roles of T helper 17 cells and Interleukin-17 in neuroautoimmune diseases with emphasis on multiple sclerosis and guillainbarr e syndrome as well as their animal models. J. Neurosci. Res. 2013, 91, 871-881.

28. Fernandes, E.S.; Passos, G.F.; Medeiros, R.; da Cunha, F.M.; Ferreira, J.; Campos, M.M.; Pianowski, L.F.; Calixto, J.B. Anti-inflammatory effects of compounds alpha-humulene and (-)-trans-caryophyllene isolated from the essential oil of Cordia verbenacea. Eur. J. Pharmacol. 2007, 569, 228-236.

29. Gertsch, J. Antiinflammatory cannabinoids in diet-Towards a better understanding of cb2 receptor action? Commun. Integr. Biol. 2008, 1, 26-28.

30. Pacher, P.; Mechoulam, R. Is lipid signaling through cannabinoid 2 receptors part of a protective system? Prog. Lipid Res. 2011, 50, 193-211. 
31. Howlett, A.C.; Barth, F.; Bonner, T.I.; Cabral, G.; Casellas, P.; Devane, W.A.; Felder, C.C.; Herkenham, M.; Mackie, K.; Martin, B.R.; et al. International union of pharmacology. XXVII. Classification of cannabinoid receptors. Pharmacol. Rev. 2002, 54, 161-202.

32. McLafferty, F.W. Wiley Registry of Mass Spectral Data, 8th ed.; Hoboken, N.J., Ed.; John Wiley \& Sons: New York, NY, USA, 2008.

33. Pick, E.; Mizel, D. Rapid microassays for the measurement of superoxide and hydrogen peroxide production by macrophages in culture using an automatic enzyme immunoassay reader. J. Immunol. Methods 1981, 46, 211-226.

34. Green, L.C.; Wagner, D.A.; Glogowski, J.; Skipper, P.L.; Wishnok, J.S.; Tannenbaum, S.R. Analysis of nitrate, nitrite, and [15n]nitrate in biological fluids. Anal. Biochem. 1982, 126, 131-138.

Sample Availability: Samples of the compounds are not available from the authors.

(C) 2013 by the authors; licensee MDPI, Basel, Switzerland. This article is an open access article distributed under the terms and conditions of the Creative Commons Attribution license (http://creativecommons.org/licenses/by/3.0/). 